\title{
Atdişi ve Sert Mısırda Yaprak Sıyırma ve Uç Almanın Verim ve Bazı Tane Özelliklerine Etkisi
}

\author{
Merve AKDOĞAN ${ }^{1}$ (D), Burhan KARA ${ }^{* 2}$ \\ ${ }^{1}$ Isparta Uygulamalı Bilimler Üniversitesi, Lisansüstü Eğitim Enstitüsü, Isparta \\ ${ }^{2}$ Isparta Uygulamalı Bilimler Üniversitesi Ziraat Fakültesi Tarla Bitkileri Bölümü, Isparta
}

Öz: Çalışma; mısırda yaprak sıyırma, uç alma ve ikisinin birlikte uygulamalarının tane verimi ve bazı tane özelliklerine etkisini araştırmak amacıyla 2018 ve 2019 yıllarında yürütülmüştür. Deneme, tesadüf bloklarında bölünmüş parseller deneme desenine göre, ana parsellere çeşitler (Bora-atdişi ve Karadeniz Yıldızı-sert mısır) ve alt parsellere uygulamalar gelecek şekilde 3 tekerrürlü kurulmuştur.

Yaprak sıyırma (YS), uç alma (UA) ve yaprak sıyırma+uç alma (YS+UA) uygulamaları her iki çeşitte de kontrole göre verim ve tane boyutlarını pozitif etkilemiştir. En yüksek tane genişliği (sırasıyla, 5.25 ve $5.58 \mathrm{~mm}$ ), tane boyu (sırasıyla, 9.89-10.21 $\mathrm{mm}$ ), koçanda tane sayısı (sırasıyla, 642.2 ve 659.6 adet), 1000 tane ağırlığı (sırasıyla, 412.9 ve $416.6 \mathrm{~g}$ ), hektolitre ağırlığı (sırasıyla, 74.9-75.2 kg) ve tane verimi (sırasıyla, 1268.3 ve $1334.8 \mathrm{~kg} \mathrm{da}^{-1}$ ) atdişi mısırda YS+UA uygulamasında belirlenmiştir. Ancak YS+UA ve UA uygulamaları aynı istatistik grupta yer almıştır. Genel olarak, her iki mısır çeşidinde de en düşük verim ve tane özellikleri kontrol parselinde tespit edilmiştir. Uç alma uygulaması verim ve tane boyutları üzerine pozitif etkilerinden dolayı önerilebilir.

Anahtar Kelimeler: Zea mays L., tane iriliği, fiziksel özellikler

\section{Effect on Yield and Some Seed Characteristics of Leaf and Tassel Removal in Dent and Flint Corn}

\begin{abstract}
The research was carried out with the aim to investigation the effects on grain yield and some seed characteristics of leaf, tassel removal and together treatments in maize during 2018 and 2019 years. The experiments were set up according to a Randomized Complete Block Design in a split-plot arrangement with three replicates, where cultivars were in the main plots while the practices were in subplots within the main plots using Bora (dent corn) and Karadeniz Yıldızı (flint corn) maize cultivars.

Effect on yield and seed characteristics of leaf (LR) and tassel removal (TR) and leaf $x$ tassel removal interaction (LRxTR) were positive in both cultivars. The highest seed width (5.25 and $5.58 \mathrm{~mm}$, respectively), seed length (9.89 and $10.21 \mathrm{~mm}$, respectively), seed number per ear (642.2 and 669.6 number, respectively), 1000 grain weight (412.9 and $416.6 \mathrm{~g}$, respectively), hectoliter weight (74.9 and $75.2 \mathrm{~kg}$, respectively) and grain yield (1268.3 and $1334.8 \mathrm{~kg} \mathrm{da}^{-1}$, respectively) were determined from the LRxTR interaction on dent corn in both years. However, YS+UA and UA treatments were included in the same statistical group. Generally, the lowest yield and seed characteristics were recorded in control treatment. The tassel removal treatment could be recommended due to its positive effects on yield and seed characteristics.
\end{abstract}

Keywords: : Zea mays L., seed size, physical characteristics

\section{GíRiş}

Mısır dünyada tüm tahıllar içinde en yüksek verimi sağlayan, güneş enerjisini en iyi kullanan (C4 bitkisi) ve birim alandan en fazla kuru madde üreten bir bitkidir (Berzy ve ark., 1997). Mısırda verim; asimilasyon hızı ve üretilen asimilat miktarının yanında su, ışık, sıcaklık, karbondioksit ve bitki besin maddeleri gibi çevre faktörleriyle, hücre fizyolojisi, yaprak alanı ve şekli gibi morfolojik özelliklerin doğrudan ya da dolaylı etkisi altındadır (Donald, 1962; Çelik, 1998). Birçok bitkide olduğu gibi mısırda da verim, yapraklardan ve diğer fotosentetik organlardan koçana besin maddesi taşınmasına bağlıdır.

Mısır, yaprak boyutları ve toplam fotosentez yüzeyi bakımından tahıllar içerisinde en yüksek değere sahip bir bitkidir (Aldrich ve ark., 1982). Mısır bitkisinde yaprakların yanı sıra yaprak kını, yaprak sapı, sap ve generatif organlar (koçan yaprağı) da fotosentez yapmakla birlikte besin maddesi üretimine önemli ölçüde katkıda bulunmaktadır. Yaprakların yaşlanması ve sararmaya başlamasından itibaren bu organların fotosentetik etkinliği ve organik maddelerin mobilizasyonu azalmakta, yaşlanan organlar tüketici konumuna düşmektedir (Edje, 1983 ve Berzy ve ark., 1997). Bu nedenle yaprak örtüsünde tutulan ışık enerjisi miktarı, bu ışık enerjisinin kuru madde verimine dönüşmesi ve üretilen kuru maddenin bitkinin hasat edilen kısımlarıyla (koçan) diğer kısımlara taşınması ve depolanması gibi verim ve kalite özelliklerine etki eden fizyolojik araştırmalar önem taşımaktadır (Hay ve Walker, 1989). Bilindiği gibi güneş ışığının büyük bir kısmı yaprak ayası tarafından tutulmakta ve diğer koşulların uygun olması durumunda ışık yoğunluğunun artması, fotosentez kapasitesini doğal olarak yükseltmektedir. Işık yoğunluğundaki artışa paralel olarak asimilasyon yüzeyinin genişliği de fotosentetik etkinliği artırmakta, bu nedenle alt

*Sorumlu Yazar: burhankara@isparta.edu.tr. Bu çalışma yüksek lisans tez ürünüdür.

Geliş Tarihi: 18 Nisan 2020

Kabul Tarihi: 24 Aralık 2020 
yaprakları daha geniş olan mısır bitkisinin fotosentez aktivitesi de daha yüksek olmaktadır (Schmidt ve Colville, 1967). Edje (1983) ve Berzy ve ark. (1997) mısırda tepe püskülünün besin maddesi tükettiği ve uzaklaştırılmasının verime katkı yaptığı bildirmişlerdir. Araştırma at dişi ve sert mısırda gelişmenin belirli devrelerinde sonra yaprak sıyırma (süt olum sonu) ve tepe püskülünün uzaklaştırmanın (tozlaşmadan sonra) verim ve tane özelliklerine etkisini araştırmak amacıyla yürütülmüştür.

\section{MATERYAL VE YÖNTEM}

Araştırma, Isparta il merkezinde 2018 ve 2019 yıllarında, Atdişi "Bora F1" ve sert mısır "Karadeniz Yıldızı F1" mısır çeşitleri kullanılarak tesadüf bloklarında bölünmüş parseller deneme desenine göre ana parsellere çeşitler, alt parsellere yaprak sıyırma, uç alma ve yaprak sıyırma+uç alma uygulamaları gelecek şekilde 3 tekerrürlü olarak yürütülmüştür.

Denemenin yürütüldüğü 2018 ve 2019 yıllarının vejetasyon süresinde (Mayıs-Eylül) ortalama sıcaklık (sırasıyla, 21.2 ve $21.2{ }^{0} \mathrm{C}$ ), uzun yıllar ortalaması ise $20.7{ }^{\circ} \mathrm{C}$ olarak gerçekleşmiştir. Mayıs-Eylül ayları içerisinde toplam yağış miktarı (sırasıyla, 126.2-152.2 mm) uzun yıllar ortalamasından (111.5 mm) yüksek olmuştur. Aynı dönemde ortalama nispi nem oranı (sırasıyla, \%51.3 ve $\% 50.2)$ uzun yıllar ortalamasına (\%48.1) yakın olmuştur (Çizelge 1).

Deneme alanı toprağı kumlu-tınlı bir yapıya sahip olup, hafif bazik ( $\mathrm{pH}$ : 7.8 ve 7.9 ), kireç oranı yüksek (\%22.7 ve 23.4 ) ve organik madde oranı (\%1.8 ve 1.6) düşüktür.

Parsel sıra uzunluğu $5 \mathrm{~m}$ ve 4 sıra, bloklar arasında $2 \mathrm{~m}$ ve her parsel arasında bir sıra aralık bırakılmıştır. Deneme, 70 $\mathrm{cm}$ sıra arası ve $20 \mathrm{~cm}$ sıra üzeri mesafede $(70 \mathrm{~cm} \times 20 \mathrm{~cm})$, her ocağa iki tohum gelecek şekilde $3-4 \mathrm{~cm}$ derinliğinde Mayıs ayının ilk haftasında (6 Mayıs 2018 ve 4 Mayıs 2019) kurulmuştur. Çıkıştan sonra her ocakta bir bitki kalacak Çizelge 1. Deneme yıllarının ve alanının bazı iklim verileri*

\begin{tabular}{|c|c|c|c|c|c|c|c|}
\hline \multirow[b]{2}{*}{ İklim verileri } & \multirow{2}{*}{ Yıllar } & \multicolumn{5}{|c|}{ Aylar } & \multirow{2}{*}{$\begin{array}{l}\text { Toplam } \\
\text { veya ort. }\end{array}$} \\
\hline & & Mayıs & Haziran & Temmuz & Ağustos & Eylül & \\
\hline Ortalama & 2018 & 16.8 & 20.0 & 24.3 & 24.3 & 20.6 & 21.2 \\
\hline \multirow{2}{*}{$\begin{array}{l}\text { Sıcaklık } \\
\left({ }^{\circ} \mathrm{C}\right)\end{array}$} & 2019 & 17.0 & 20.6 & 23.4 & 24.4 & 19.9 & 21.1 \\
\hline & Uzun yıllar & 15.6 & 20.2 & 23.6 & 25.8 & 18.3 & 20.7 \\
\hline \multirow{3}{*}{$\begin{array}{l}\text { Yağış } \\
(\mathrm{mm})\end{array}$} & 2018 & 34.2 & 53.3 & 9.5 & 2.7 & 26.5 & 126.2 \\
\hline & 2019 & 62.9 & 69.4 & 4.1 & 14.2 & 1.6 & 152.2 \\
\hline & Uzun yıllar & 51.4 & 29.8 & 14.6 & 0.3 & 15.4 & 111.5 \\
\hline \multirow{3}{*}{ Nisbi nem (\%) } & 2018 & 52.3 & 62.4 & 46.9 & 47.6 & 47.4 & 51.3 \\
\hline & 2019 & 53.0 & 59.9 & 44.7 & 42.9 & 50.5 & 50.2 \\
\hline & Uzun yıllar & 50.3 & 53.0 & 45.8 & 43.6 & 47.8 & 48.1 \\
\hline
\end{tabular}

şekilde tekleme yapılmıştır. Ekimle birlikte taban gübresi saf olarak $15 \mathrm{~kg} \mathrm{da}{ }^{-1}$ olacak şekilde 15-15-15 gübresi, çapalamayla birlikte bitki diz boyu $(35-40 \mathrm{~cm})$ döneminde üst gübre yine saf olarak $12 \mathrm{~kg} \mathrm{da}^{-1}$ üre uygulanmıştır (Kara ve Kırtok, 2006). Ekimden sonra çıkış yapana kadar ve çıkıştan sonra toprak nem düzeyi kontrol edilerek damlama sulama yöntemi ile sulanmıştır.

Uygulamalar: 1. Kontrol; yapak sıyırma ve uç alma uygulaması yapılmamış, 2. Yaprak sıyırma (YS); süt olum dönemi sonunda sararmış alt yapraklar ve daha sonra sararan yapraklar kontrol edilip ilk koçana kadar olan yapraklar uzaklaştırılmış, 3. Uç alma (UA); tozlaşmadan sonra koçan püskülleri kahverengi durumunu aldıktan sonra tepe püskülü kesilerek uzaklaştırılmış ve 4. Yaprak sıyırma+uç alma (YS+UA); süt olum dönemi sonunda sararmış alt yapraklar ve tozlaşmadan sonra koçan püskülleri uzaklaştırma şeklinde uygulamamlar yapılmıştır.

Tane hasat döneminde (nem yaklaşık \%13-14) kenar tesirleri atıldıktan sonra tüm parseldeki koçanlar elle hasat (30 Ekim 2018 ve 24 Ekim 2019) edilmiştir. Hasat edilen her parselden koçanın orta kısmından 50 adet tanenin kumpas ile tane genişliği $(\mathrm{mm})$, tane boyu $(\mathrm{mm})$ ölçülmüştür. Buna ilaveten 1000 tane ağırlığı (g), koçanda tane sayısı (adet), hektolitre ağırlığı $(\mathrm{kg})$ ve tane verimi $\left(\mathrm{kg} \mathrm{da}^{-1}\right)$ ölçülmüştür. Elde edilen verilerin varyans analizleri SAS istatistik paket programından faydalanılarak yapılmış ve ortalamalar arasındaki farkların önem düzeyleri DUNCAN Testi ile belirlenmiştir.

\section{BULGULAR VE TARTIŞMA}

Yaprak sıyırma, uç alma ve bunların birlikte uygulanmasının atdişi ve sert mısırın verim ve bazı tane özelliklerine etkisi çeşitlere ve uygulamalara göre değişmiştir (Çizelge 2). Tane boyu, koçanda tane sayısı ve hektolitre ağırlığı bakımından yıllar arasında istatistiksel olarak fark olmazken, tane genişliği, 1000 tane ağırlığı ve tane verimi bakımından fark 
Çizelge 2. Yaprak sıyırma, uç alma ve bunların birlikte uygulamalarının mısırın verim ve bazı tane özelliklerine etkisi

\begin{tabular}{|c|c|c|c|c|c|c|c|}
\hline \multirow{2}{*}{\multicolumn{2}{|c|}{ Çeşitler x Uygulama }} & \multicolumn{2}{|c|}{ Tane genişliği (mm) } & \multicolumn{2}{|c|}{ Tane boyu (mm) } & \multicolumn{2}{|c|}{ Koçanda tane sayısı (adet) } \\
\hline & & \multirow{2}{*}{$\begin{array}{l}2018 \\
4.57 d\end{array}$} & \multirow{2}{*}{$\begin{array}{l}2019 \\
4.62 \mathrm{c}\end{array}$} & \multirow{2}{*}{$\begin{array}{l}2018 \\
8.15 d\end{array}$} & \multirow{2}{*}{$\begin{array}{l}2019 \\
8.76 \mathrm{e}\end{array}$} & \multirow{2}{*}{$\begin{array}{l}2018 \\
618.1 b\end{array}$} & \multirow{2}{*}{$\begin{array}{l}2019 \\
605.6 \mathrm{~d}\end{array}$} \\
\hline Karadeniz & Kontrol & & & & & & \\
\hline Yıldızı & YS & $4.80 \mathrm{c}$ & $4.92 \mathrm{~b}$ & $8.29 \mathrm{~d}$ & $9.34 \mathrm{~d}$ & $603.3 \mathrm{~b}$ & $607.6 \mathrm{~d}$ \\
\hline \multirow[t]{3}{*}{ (sert mısır) } & UÇ & $4.93 \mathrm{~b}$ & $5.55 \mathrm{a}$ & $9.12 \mathrm{c}$ & $9.42 \mathrm{~d}$ & $589.6 \mathrm{c}$ & $619.3 \mathrm{c}$ \\
\hline & YS+UÇ & $5.05 b$ & $5.59 \mathrm{a}$ & $9.36 \mathrm{c}$ & $9.72 b$ & $611.4 \mathrm{~b}$ & $623.3 \mathrm{c}$ \\
\hline & Kontrol & $4.62 \mathrm{~d}$ & $4.95 b$ & $9.65 \mathrm{~b}$ & $9.62 \mathrm{c}$ & $635.1 \mathrm{a}$ & $624.6 \mathrm{c}$ \\
\hline Bora & YS & $4.87 \mathrm{bc}$ & $4.72 \mathrm{c}$ & $9.70 \mathrm{~b}$ & 9.92 a & 638.9 a & $646.3 \mathrm{~b}$ \\
\hline \multirow[t]{2}{*}{ (atdişi) } & UÇ & $4.95 \mathrm{~b}$ & $5.65 a$ & 9.79 a & $10.18 \mathrm{a}$ & $640.3 a$ & $657.3 \mathrm{a}$ \\
\hline & YS+UÇ & $5.25 \mathrm{a}$ & $5.58 \mathrm{a}$ & $9.89 a$ & $10.21 \mathrm{a}$ & $642.2 \mathrm{a}$ & $659.6 \mathrm{a}$ \\
\hline \multicolumn{2}{|c|}{ F değeri çeşit x Uygulama } & $6.15^{*}$ & $5.30^{*}$ & $8.97 * *$ & $10.62 * *$ & $9.12 * *$ & $11.69 * *$ \\
\hline \multicolumn{2}{|c|}{ Yıl ortalama } & $4.86 \mathrm{~B}$ & $5.19 \mathrm{~A}$ & 9.24 & 9.64 & 622.2 & 631.5 \\
\hline \multicolumn{2}{|l|}{ F değeri ${ }_{Y ı l}$} & \multicolumn{2}{|c|}{$6.87^{*}$} & \multicolumn{2}{|c|}{$1.58^{\text {öd }}$} & \multicolumn{2}{|c|}{$2.42^{\text {öd }}$} \\
\hline \multirow[t]{2}{*}{ Çeşitler } & K. Yıldızı & 4.83 & 5.17 & 8.73 & $9.31 \mathrm{~B}$ & $605.6 \mathrm{~B}$ & 613.9 B \\
\hline & Bora & 4.92 & 5.22 & 9.77 & $9.98 \mathrm{~A}$ & $639.1 \mathrm{~A}$ & $643.4 \mathrm{~A}$ \\
\hline \multirow[t]{3}{*}{ F değeri çeşit } & & $1.28^{\text {öd }}$ & $0.07^{\text {öd }}$ & $1.12^{\text {öd }}$ & $52.98^{* *}$ & $22.14^{* *}$ & $59.03 * *$ \\
\hline & Kontrol & $4.59 \mathrm{C}$ & $4.78 \mathrm{~B}$ & $8.90 \mathrm{~B}$ & $9.19 \mathrm{C}$ & 626.3 & 619.1 \\
\hline & YS & $4.76 \mathrm{~B}$ & $4.82 \mathrm{~B}$ & $8.99 \mathrm{~B}$ & $9.63 \mathrm{~B}$ & 622.7 & 627.1 \\
\hline \multirow[t]{2}{*}{ Uygulamalar } & UÇ & $4.94 \mathrm{~A}$ & $5.60 \mathrm{~A}$ & $9.45 \mathrm{~A}$ & $9.80 \mathrm{~A}$ & 614.9 & 638.3 \\
\hline & YS+UÇ & $5.15 \mathrm{~A}$ & $5.59 \mathrm{~A}$ & $9.62 \mathrm{~A}$ & $9.95 \mathrm{~A}$ & 625.1 & 641.5 \\
\hline \multicolumn{2}{|c|}{ F değeri Uygulama } & $11.21^{* *}$ & $4.95^{*}$ & $6.60^{*}$ & $12.74^{* *}$ & $1.28^{\text {öd }}$ & $2.82^{\text {öd }}$ \\
\hline \multicolumn{2}{|c|}{ VK (\%) } & 7.14 & 9.63 & 5.48 & 2.32 & 7.97 & 2.23 \\
\hline Cesitler x Uvg & lama & $1000 \tan$ & rlığı (g) & Hektoli & rlığı (kg) & Tane verir & $\left.\mathrm{da}^{-1}\right)$ \\
\hline 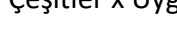 & Iallia & 2018 & 2019 & 2018 & 2019 & 2018 & 2019 \\
\hline Karadeniz & Kontrol & $357.6 \mathrm{c}$ & $374.1 d$ & $71.5 \mathrm{~b}$ & $70.9 c$ & $1164.8 \mathrm{~b}$ & $1202.6 c$ \\
\hline Yıldızı & YS & $369.3 \mathrm{c}$ & $368.7 d$ & $73.6 \mathrm{a}$ & $72.2 b$ & $1169.9 \mathrm{~b}$ & $1232.7 b$ \\
\hline (sert mısır) & UÇ & 387.5ab & $400.4 \mathrm{c}$ & $72.4 \mathrm{~b}$ & 73.5ab & $1187.4 \mathrm{~b}$ & $1211.4 c$ \\
\hline & YS+UÇ & 384.9 b & $390.0 \mathrm{c}$ & $73.9 \mathrm{a}$ & 73.3ab & $1216.8 \mathrm{a}$ & $1240.5 b$ \\
\hline Bora & Kontrol & 392.6ab & $395.8 c$ & $72.2 \mathrm{~b}$ & $72.7 b$ & $1171.7 \mathrm{~b}$ & $1244.7 b$ \\
\hline (atdişi) & YS & 389.9ab & $399.1 c$ & $73.1 \mathrm{a}$ & $72.5 b$ & $1189.6 \mathrm{~b}$ & $1248.6 b$ \\
\hline & UÇ & 397.8 a & $411.6 \mathrm{~b}$ & $73.8 \mathrm{a}$ & $73.8 \mathrm{ab}$ & $1248.7 \mathrm{a}$ & $1334.8 \mathrm{a}$ \\
\hline & YS+UÇ & $412.9 \mathrm{a}$ & $416.6 a$ & $74.9 \mathrm{a}$ & $75.2 a$ & $1268.3 \mathrm{a}$ & $1323.3 a$ \\
\hline F değeri çeşit x & gulama & $13.24 * *$ & $9.02 * *$ & $6.71^{*}$ & $7.73^{*}$ & $12.87^{* *}$ & $11.36^{* *}$ \\
\hline Yıl ortalama & & $384.3 B$ & $397.1 \mathrm{~A}$ & 73.2 & 72.8 & 1202.1B & $1263.2 \mathrm{~A}$ \\
\hline F değeri Yıl $_{1}$ & & & & & & & \\
\hline Çeşitler & K. Yıldızı & $374.8 \mathrm{~B}$ & $383.3 B$ & 73.1 & $72.4 \mathrm{~B}$ & 1184.7B & 1123.2B \\
\hline & Bora & 398.3A & 410.8A & 73.6 & $74.3 \mathrm{~A}$ & 1219.6A & $1288.1 \mathrm{~A}$ \\
\hline F değeri çeşit & & $6.88^{*}$ & $27.18^{* *}$ & $0.76^{\text {öd }}$ & $5.43^{*}$ & $8.71^{*}$ & $7.84^{*}$ \\
\hline & Kontrol & $375.1 \mathrm{~B}$ & $385.1 B$ & $71.8 \mathrm{~B}$ & $71.3 \mathrm{C}$ & $1168.2 \mathrm{~B}$ & $1255.3 B$ \\
\hline & YS & $379.6 \mathrm{~B}$ & $383.9 B$ & $73.3 \mathrm{~A}$ & $72.3 B C$ & 1179.7 B & $1240.2 A B$ \\
\hline Uygulamalar & UÇ & $392.6 A$ & $406.4 \mathrm{~A}$ & $73.1 \mathrm{~A}$ & 73.7AB & $1218.0 \mathrm{~A}$ & $1290.1 \mathrm{~A}$ \\
\hline & YS+UÇ & $389.9 A$ & $413.3 \mathrm{~A}$ & $74.4 \mathrm{~A}$ & $74.2 \mathrm{~A}$ & $1242.5 \mathrm{~A}$ & 1267.4AB \\
\hline F değeri Uygula & & $5.47^{*}$ & 7.94* & $6.26^{*}$ & $8.75^{*}$ & $17.12^{* *}$ & $6.56^{*}$ \\
\hline VK (\%) & & 6.12 & 3.25 & 4.89 & 2.49 & 9.24 & 7.53 \\
\hline
\end{tabular}

YS: Yaprak sıyırma, UÇ: Uç alma, ${ }^{*}{ }^{* *}$ : Sırasıyla P $\leq 0.05, \mathrm{P} \leq 0.01$ düzeyinde önemli, öd: önemli değil

Aynı sütunda benzer harfler ile gösterilen ortalamalar arasında istatistiksel olarak fark yoktur. 
çıkmış ve ikinci yıl ortalama değerleri birinci yıldan daha yüksek olmuştur. Mısır bitkisi her ne kadar yetiştirme döneminde sulanmış olsa da, ikinci yılın yağış miktarının bir miktar fazla olması suyu seven bir bitkide verimi artırabilir. Mısır bitkisinde yağış miktarının fazla olduğu yılda daha düşük olan yıla göre verimin bir miktar yüksek olduğunu bildiren araştırmalar mevcuttur (Atar ve Kara, 2017; Güney ve Tan, 2019).

Her iki yılda da, Bora çeşidinin verim ve incelenen tane özellikleri Karadeniz Yıldızı çeşidinden daha yüksek olmuştur (Çizelge 2). Ancak çeşitlerin birinci yıla ait tane genişliği, tane boyu ve hektolitre ağılıkları arasında istatistiksel olarak fark çıkmamıştır.

Çalışmada kullanılan Karadeniz Yıldızı çeşidinin (sert mısır) tane boyutlarının büyük olduğu, atdişi mısır boyutlarına yakın olduğu gözlemlenmiştir. Çeşitlerin tane boyutları arasında farkın çıkmamasının nedeni koçandaki tane sayısına bağlı olabilir. Çünkü daha iri koçan yapısına sahip olan atdişi mısırda tane sayısının daha fazla olması tohumların biraz daha küçük kalmasına neden olabilir. Ancak bütün koçan değerlendirildiğinde, tür özelliğine bağlı olarak atdişi (Bora) mısırın tane boyutları daha büyük olması bin tane ağırlığı, hektolitre ağırlığı ve tane veriminde kendini göstermiştir. Öner ve ark. (2012), Sakin ve ark. (2016), Atakul ve ark. (2017), Kökten ve Akçura (2017) ve Gür ve Kara (2019) mısırda tane verimini alt türlere ve çeşitlere göre değiştiğini bildirmişlerdir.

Mısırda YS ve UA ile bunların birlikte uygulamasının koçanda tane sayısı dışında incelenen özelliklere etkisi istatistiksel olarak önemli olmuştur. Genel olarak kontrole göre tüm uygulamada mısırın tane boyutları ve verimi yükselmiştir. Koçanda tane sayısı ise uygulamalardan etkilenmemiştir. Bunun nedeninin mısırda sıra sayısı ile ilişkili olduğu düşünülmektedir. Turgut ve ark. (1995) koçanda sıra sayısı daha çok genetik bir özellik olduğunu, Esmeray (2016) koçanda sıra sayısı üzerinde genetik etkenlerin payının, çevre etkenlerinden daha fazla olduğu bildirmişlerdir. Mısırda sıra sayısı ile tane sayısı arasında yüksek ilişki vardır (Şekeroğlu ve ark., 2000). Bu nedenle koçanda tane sayısı, sıra sayısına bağlanabilir.

Genel olarak her iki çeşitte de UA ile YS+UA ortalamaları birebirine yakın olurken, YS uygulaması ortalamalarının daha düşük olduğu söylenebilir. Bunun nedeni her ne kadar yapraklar sararma başladığında koparılsa da yaprakların bir fotosentez organı olması incelenen özellikleri olumsuz etkilemiş olabilir. UA uygulamasında ise verim ve tane özellikleri yükseldiği görülmüştür. Edje (1983) ve Berzy ve ark. (1997) mısırda tepe püskülünün besin maddesi tükettiği ve uzaklaştırılmasının verimi artırdığını bildirmişlerdir. Kara ve Akman (2002) şeker mısırda uç alma uygulaması koçan çapını, yaprak sıyırma uygulaması ise koçan ağırlığını pozitif yönde etkilediğini bildirmişlerdir. Sangoi ve Salvador (1998) mısırda tepe püskülünün koparılmasının tane verimine önemli bir etkisinin olmadığını bildirmiştir.

Çeşit x uygulama kombinasyonu değerlendirildiğinde, her iki çeşitte de YS, UA ve bunların birlikte uygulaması kontrole göre verim ve tane özelliklerine pozitif etki yapmıştır. Araştırmada yılara bağlı olarak birinci yıl tane genişliği 4.57$5.25 \mathrm{~mm}$, tane boyu $8.15-9.89 \mathrm{~mm}$, koçanda tane sayısı 589.6-642.2 adet, 1000 tane ağırlığı 357.6-412.9 g, hektolitre ağırlığı 71.5-74.9 kg ve tane verimi 1164.8-1268.3 $\mathrm{kg} / \mathrm{da}$ arasında, ikinci yıl bu özellikler sırasıyla, 4.62-5.65 $\mathrm{mm}, 8.76-10.21 \mathrm{~mm}, 605.6-659.6$ adet, 368.7-416.6 g, 70.9$74.2 \mathrm{~kg}$ ve $1202.6-1334.8 \mathrm{~kg} \mathrm{da}^{-1}$ arasında değişmiştir (Çizelge 2). Bu özelliklerin en yüksek değerleri Bora çeşidinde UA ile YS+UA birlikte uygulamasında belirlenmiştir. Genel olarak en düşük değerler ise kontrol uygulamasında belirlenmiştir. Bir atdişi mısır çeşidi olan Bora çeşidinin sert mısıra (Karadeniz Yıldızı) göre tür olarak daha büyük tane özelliklerine sahip olmasından dolayı verimi ve tane özellikleri daha yüksek olmuştur.

\section{SONUÇ}

Mısırda YS, UA ve bunların birlikte uygulamaları, kontrole göre mısırın incelenen tane özelliklerine ve verimine olumlu etki yapmıştır. Araştırmada, UA ile YS+UA uygulamalarının incelenen tüm özelliklere etkisi istatistiksel olarak benzer olmuştur. Bu nedenle mısırda YS ve YS+UA uygulamalarına gerek olmadığı ve yalın uç almanın önerilebilir olduğu sonucuna varılmıştır. Uygulamalar arasında önerilen uç alma, kontrole göre tane veriminde birinci yıl \%4.1 ve ikinci yıl \%3.8 oranında artırmıştır. Sonuç olarak, mısırda özellikle tohumluk üretiminde tane iriliğini artırmak için bu uygulamalardan faydalanılabilir.

\section{KAYNAKLAR}

Aldrich SR, Scott WO, Leng ER (1982) Modern Corn Production A \& L Publications, Illinois, S: 100-105, U.S.A.

Atakul Ş, Kılınç S, Kahraman Ş (2017) Diyarbakır Ana Ürün Koşullarında Bazı Tane Mısır Genotiplerinin Verim ve Verim Unsurlarının Belirlenmesi. Bahri Dağdaş Bitkisel Araştırmalar Dergisi 6: 35-47.

Atar B, Kara B (2017) Farklı Derinliklerde Çizilere Ekimin Şeker Mısırın Taze Koçan Verimi ve Bazı Koçan Özelliklerine Etkisi. Derim 34(2): 182-185.

Berzy T, Szundy T, Pinter J, Feher C (1997) Effect of Tassel Damage at the Beginning of Female Flovering on the Yield on Quality of Maize (Zea mays L). Seed Science and Technology 25: 35-44.

Çelik N (1998) Ürün Fizyolojisi. U. Ü. Ziraat Fakültesi Ders Notları, No:79, s: 36-39, Bursa.

Donald CM (1962) In Research of Yield. Journal of Australian Agriculture Science 28: 171-178.

Edje OT (1983) Effect of Tassel Removal and Defoliation of Maize on Yield of Maize and Bean Grown on Monoculture and in Association. Malawi University Research Bulletin 12: 69-85. 
Esmeray M (2016) Mısır Heterotik Gruplarında Genetik Analizler. Doktora Tezi, Namık Kemal Üniversitesi, Tekirdağ.

Güney E, Tan M (2019) Yüksek Rakımda Farklı Olgunlaşma Süresine Sahip Silajlık Mısır Çeşitlerinin Ekim Zamanlarının Belirlenmesi. Uluslararası Tarım ve Yaban Hayatı Bilimleri Dergisi 5(2): 314-321.

Gür i, Kara B (2019) Trabzon Ekolojik Koşullarında Atdişi Hibrit Mısır Çeşitlerinin Performansları. Black Sea Journal of Agriculture 2(2): 103-108.

Hay RKM, Walker AJ (1989) An Introduction to the Physiology of Crop Yield. Co published in the United States With John Wiley\&Sons, Inc., p: 39-40, New York.

Kara B, Akman Z (2002) Şeker Mısırında (Zea mays saccharata Sturt.) Koltuk ve Uç Alma ile Yaprak Sıyırmanın Verim ve Koçan Özelliklerine Etkisi. Akdeniz Üniversitesi Ziraat Fakültesi Dergisi 15(2): 918.

Kara B, Kırtok Y (2006) Çukurova Koşullarında Değişik Bitki Sıklıkları ve Farklı Azot Dozlarında Mısırın Tane Verimi ile Azot Alım ve Kullanım Etkinliğinin Belirlenmesi. Çukurova Üniversitesi Ziraat Fakültesi Dergisi 21(2): 23-32.

Kökten K, Akçura M (2017) Performances of Hybrid Dent Maize Cultivars in Bingöl Conditions. Süleyman Demirel Üniversitesi Fen Bilim Enstitüsü Dergisi 21(1):261-265.
Öner F, Sezer I, Gülümser A (2012) Farklı Lokasyonlarda Yetiştirilen Atdişi Mısır (Zea mays L. indendata) Çeşit ve Hatlarının Agronomik Özellikler Yönünden Karşılaştırılması. Tekirdağ Ziraat Fakültesi Dergisi 9(2): 1-6.

Sakin MA, Bozdağ M, Çakar Ş (2016) Tokat Kazova ve Zile Ana Ürün Koşullarında Yetiştirilen Melez Atdişi Mısır (Zea mays indentata L.) Çeşitlerinin Verim ve Verim Özelliklerinin Belirlenmesi. Tarla Bitkileri Merkez Araştırma Enstitüsü Dergisi 25 (Özel sayı): 87-93.

Sangoi L, Salvador RJ (1998) Effect of Maize Plant Tasseling on Grain Yield, Tolerance to High Plant Density and Drought Stress. Dep. De Fitotec., Uni do Estado de Santa Cetarina, Pesquisa Agronomic 33: 677-684.

Schmidt WH, Colville WL (1967) Yield and Yield Components of Zea mays L. as Influenced by Artificially Induced Shade. Crop Science 7: 128-130.

Şekeroğlu N, Dede Ö, Deveci M, Kara ŞM (2000) Melez Mısır Populasyonlarında Verim ve Verim Unsurları Arasındaki illişkilerin Path Analizi ile Belirlenmesi. Gaziosmanpaşa Üniversitesi Ziraat Fakültesi Dergisi 17(1): 79-82.

Turgut I, Yüce S, Altınbaş M (1995) Dokuz Kendilenmiş Mısır Hattının Diallel Melezlerinde Bazı Tarımsal Özelliklerin Kalıtımları, Dane Verimi ve Verim Öğeleri. Anadolu 5(1): 74-92. 
